\section{Unbalanced bilingual acquisition as a mechanism of grammatical change*}

Bilingual first language acquisition (BFLA) has been considered a possible mechanism of contact-induced change in several recent studies (Siegel, 2008, p. 117; Satterfield, 2005, p. 2075; Thomason, 2001, p. 148; Yip \& Matthews, 2007, p.15). There is as yet little consensus on the question, with divergent views regarding both BFLA at the individual level and the implications for language change at the community level.

The keynote article by Meisel (henceforth $\mathrm{M}$ ) is a welcome contribution to this discussion. We especially applaud his tackling the fundamental questions of learnability as they arise in the context of BFLA, and specifically the issue of when and how "acquisition failure" (or divergence) can occur. Whereas accounting for uniform convergence in first language acquisition requires unambiguous triggers (Fodor, 1998), divergent outcomes in the course of BFLA could result from ambiguous data, as $\mathrm{M}$ notes. This forms part of what we have called the LOGICAL PROBLEM OF BILINGUAL ACQUISITION (Yip \& Matthews, 2007, p. 31): a theory of BFLA must allow for divergence from, as well as convergence with, the target grammar. In principle such divergence may, if circumstances are favourable, lead to grammatical change.

$\mathrm{M}$ adds clarity to this debate by distinguishing three circumstances in which bilingual acquisition could contribute to grammatical change: (a) when the data contain L2 versions of the target language, (b) in successive acquisition, and (c) in simultaneous acquisition. Case (a) is widely accepted, notably in the literature on contact languages (DeGraff, 1999; Gupta, 1994), while cases (b) and (c) are less clearly established (Siegel, 2008, p. 120). Regarding case (c), M argues that simultaneous BFLA is not a likely cause of grammatical change, at least where parameter settings are concerned. In our view, $M$ underestimates the role of BFLA as a mechanism of contactinduced change for two reasons. First, his adoption of the parameter-setting model dictates a severely limited view of what constitutes grammatical change. Second, his interpretation of the evidence on unbalanced BFLA plays

\footnotetext{
* This research is fully supported by a grant from the Research Grants Council of the Hong Kong Special Administrative Region, China (project reference no. CUHK 453808). We thank Carmen SilvaCorvalán for constructive comments on an earlier version of this commentary.
}

\author{
STEPHEN MAT THEW S \\ University of Hong Kong, Pokfulam Road, Hong Kong \\ matthews@hkucc.hku.hk \\ VIR GINIA Y IP \\ Childhood Bilingualism Research Centre, \\ Chinese University of Hong Kong, Shatin, N.T., \\ Hong Kong \\ vcymatthews@cuhk.edu.hk
}

down the role of cross-linguistic influence by invoking accounts that are far from being securely established.

While assuming an explicit theory helps to make the investigation more concrete, the parameter-setting model has been abandoned by many of its former proponents, and some features of it are especially problematic (Newmeyer, 2005). For example, binary parameters do not allow for a "third grammar" and M accordingly dismisses the possibility of intermediate grammars as stages in acquisition. But typology suggests that such intermediate grammars are possible: for example, the head parameter allows for head-initial or head-final languages, but Chinese happily combines head-initial and head-final constituents, with no evidence of change toward either type. Furthermore, the clustering of head-initial and head-final constituents is readily explained in terms of syntactic processing and production (Hawkins, 1990; Newmeyer, 2005), thus rendering the parameter itself superfluous while allowing for intermediate "settings". While M does not invoke the head parameter, he does invoke the "V2 parameter" as a determinant of constituent order; at one point, he states that V2 was "not fully grammaticalized" in Old High German, which suggests an intermediate stage there too. Even if one assumes the viability of the parametersetting model, it excludes from consideration (as $\mathrm{M}$ acknowledges) many kinds of change in which bilingual acquisition has been implicated, such as shifts in the frequency of variants (see the case of verb-particle constructions in Yip \& Matthews 2007, p. 222) and contactinduced grammaticalization (Matthews \& Yip 2009).

A second question with which we would take issue involves the interpretation of data sets on unbalanced BFLA, that is, simultaneous acquisition where there is clearly a weaker language. M's discussion of these cases is tied up with the issue of whether such acquisition is an instance of (or rather, resembles) child second language acquisition (SLA). This is unfortunate since there is no way in which a non-arbitrary distinction can be drawn between BFLA and child SLA (Yip \& Matthews, 2007, p. 25). Rather, we are faced with continuous variation with respect to at least two potentially interacting factors: (a) age of first exposure to the weaker/second language, and (b) balance in the input between the two languages (we simplify things considerably by ignoring common complications such as interrupted exposure and 
the presence of a third language). Therefore, with respect to the early stages of child language acquisition, the Fundamental Difference Hypothesis (proposed for adult SLA) cannot hold, because there is nowhere to draw the line between BFLA and SLA. M effectively acknowledges this when he suggests that child SLA resembles BFLA in some domains and adult $\mathrm{L} 2$ acquisition in others.

The debate over the status of unbalanced BFLA is, in any case, tangential to M's research question. Bonnesen (2007), for example, is concerned with the ways in which unbalanced BFLA is like first and second language acquisition respectively. His study does not address the question of cross-linguistic influence, which is crucial to the question of bilingual acquisition as a mechanism of contact-induced change. The argument that unbalanced BFLA is not a form of SLA leads $M$ to conclude that "cases of bilingual development where one language is weaker than the other(s) do not seem to be prone to lead to transmission failures of the sort which might explain reanalysis in diachronic change" (p. 133). But the validity of this conclusion depends on whether there is cross-linguistic influence between the child's developing grammars. Bonnesen's (2007) data on negation are mostly (with exceptions such as his example (21f)) consistent with his view that the weaker language in unbalanced BFLA is more like a first language, but they are also consistent with the possibility of interaction between the two systems in the form of positive transfer which, because the languages are so similar, is undetectable. When we turn to typologically divergent language pairs such as Japanese-English and Cantonese-English, interactions are unmistakable. Mishina-Mori (2005, p. 308) shows that the Japanese-English bilingual child with English as dominant language went through a stage of fronting wh-phrases in Japanese, as in (1):

(1) doko omise?

where store

"Where (is the) store?"

(Ken 3;2)

Conversely, Yip and Matthews $(2000,2007)$ document systematic transfer of wh-in-situ from Cantonese in children whose Cantonese is dominant, as in (2):

(2) He get it to where?

(Timmy 3;05;28)

To account for cases of cross-linguistic influence such as (1) and (2), M adopts two lines of argument, widely pursued in recent work (De Houwer, 2009; Nicoladis, 2006), but both inadequate in our view:

(i) It is claimed that the divergent features seen in bilingual children involve only the frequency of usage of options which are also attested in monolingual environments: thus the bilingual child's grammar may be quantitatively, but not qualitatively different from that of monolinguals. There are indeed many cases where bilingual children use, for example, null subjects and objects with different frequencies from monolingual children. But these contrasts are accompanied by qualitative differences: Cantonese-English children do not just show a general propensity to drop objects, but transfer a specific mechanism for licensing null objects from Cantonese (Yip \& Matthews, 2007, p. 146). In (3), the object this is introduced as the object of bought, then becomes the (unstated) topic of the following discourse, thereby licensing the null objects in the following two clauses, as shown in (4):

(3) You bought this for me. Last time you

bought. I know you bought.

(Timmy 2;07;11)

(4) You bought $[\text { this }]_{i}$ for me. $[\text { TOPIC }]_{i}$ last time you

bought $\mathrm{e}_{\mathrm{i}}$. [TOPIC $]_{\mathrm{i}}$ I know you bought $\mathrm{e}_{\mathrm{i}}$.

It is this mechanism, qualitatively quite unlike anything in English grammar, which underlies the qualitative differences observed.

(ii) An appeal is made to "specificities of language processing in bilingual production" (p. 133) implying that cross-linguistic influence is a matter of performance. This line of explanation (spelt out in Nicoladis, 2006) may account for sporadic, but not for systematic cases of crosslinguistic influence. For example, in our longitudinal study of Cantonese-English bilingual children, 92\% of Timmy's what questions $(\mathrm{n}=78)$ and $100 \%$ of where questions $(\mathrm{n}=20)$ produced by Sophie and Alicia throughout the corpus are in situ (Yip \& Matthews, 2007, pp. 99, 102). This is evidence for a developmental stage at which the child's transitional competence diverges from the target grammar; in parameter-setting terms, it would imply that the relevant parameter is initially set to [-wh-movement] and re-set to [ $+w h$-movement] at a later stage.

$\mathrm{M}$ also invokes variability, claiming that "no one has been able as yet to explain what causes [divergences such as the above] to happen with some children but not with others" (p. 132). Together with input ambiguity, which in principle is applicable to all children (Yip \& Matthews, 2007, p. 120), language dominance does explain why there is transfer of $w h$-movement in (1) but transfer of $w h$-in-situ in (2). Furthermore, in some domains, there is evidence that the prevalence of these features depends on the degree of dominance (see Yip \& Matthews, 2007, p. 150 for the case of null objects). Cross-linguistic influence can occur in the absence of dominance (Müller, 1998) but this merely shows that, unsurprisingly, more than one factor is implicated in cross-linguistic influence.

The variation in developmental patterns seen in simultaneous acquisition (case (c) above) is one reason to agree with $\mathrm{M}$ that cross-linguistic effects in cases (a) and (b) are more likely to contribute to grammatical change. However, individual variation does not prevent 
unbalanced BFLA from contributing to contact-induced change. If we assume the feature pool model of transmission (Mufwene, 2001), any non-target variant will be introduced into the feature pool from which variants are selected based on ecological (including functional and social) factors. The prevalence of the non-target (divergent) variant may be a factor in determining whether it spreads within a population of speakers, but there is no way to determine a threshold below which it would be negligible in language change.

A case study is offered by Singapore Colloquial English (SCE), which has been termed "a contact variety pioneered by children" (Gupta, 1994, p. 47). Most of the distinctive grammatical features of SCE have close parallels in the unbalanced bilingual development of children acquiring Cantonese and English simultaneously. This suggests that BFLA is a POSSIBLE mechanism for such changes (Yip \& Matthews, 2007, p. 262); the actual mechanisms are a function of historical circumstances, which in the case of SCE suggest that non-native input and successive acquisition were also involved (Gupta, 1994, p. 44).

In sum, M's perspective on the role of BFLA in grammatical change is limited by the assumption of a theoretical model which excludes from the outset much of contact-induced change (including anything that does not fall out from parameter settings). His assessment of unbalanced BFLA is questionable on several grounds, including a database limited to western European language pairs and the attempt to dismiss cross-linguistic influence as an unsystematic performance phenomenon. Nonetheless, $M$ has moved the debate forward by distinguishing the logic of the arguments with respect to each type of bilingualism, and formulating the issues clearly and forcefully.

\section{References}

Bonnesen, M. (2007). The status of the 'weaker' language in unbalanced French/German laguage acquisition. Bilingualism: Language and Cognition, 12, 177-192.
DeGraff, M. (1999). Creolization, language change, and language acquisition: A prolegomenon. In M. DeGraff (ed.), Language creation and language change: Creolization, diachrony, and development, pp. 1-46. Cambridge, MA: MIT Press

De Houwer, A. (2009). Bilingual first language acquisition. Clevedon: Multilingual Matters.

Fodor, J. D. (1998). Unambiguous triggers. Linguistic Inquiry, 29, 1-36.

Gupta, A. F. (1994). The step-tongue: Children's English in Singapore. Clevedon: Multilingual Matters.

Hawkins, J. A. (1990). A parsing theory of word order universals. Linguistic Inquiry, 21, 223-262.

Matthews, S., \& Yip, V. (2009). Contact-induced grammaticalization: Evidence from bilingual acquisition. Studies in Language, 33, 366-395.

Mishina-Mori, S. (2005). Autonomous and interdependent development of two language systems in Japanese/English simultaneous bilinguals: Evidence from question formation. First Language, 25, 291-315.

Mufwene, S. S. (2001). The ecology of language evolution. Cambridge: Cambridge University Press.

Müller, N. (1998). Transfer in bilingual first language acquisition. Bilingualism: Language and Cognition, 1, 151-171.

Newmeyer, F. J. (2005). Possible and probable languages. Oxford: Oxford University Press.

Nicoladis, E. (2006). Cross-linguistic transfer in adjectivenoun strings by preschool bilingual children. Bilingualism: Language and Cognition, 9, 15-32.

Satterfield, T. (2005). The bilingual bioprogram: Evidence for child bilingualism in the formation of creoles. Proceedings of 4th International Symposium on Bilingualism, pp. 20752094.

Siegel, J. (2008). The emergence of pidgin and creole languages. Oxford: Oxford University Press.

Thomason, S. G. 2001. Language contact: An introduction. Edinburgh: Edinburgh University Press.

Yip, V., \& Matthews, S. (2000). Syntactic transfer in a Cantonese-English bilingual child. Bilingualism: Language and Cognition, 3, 193-208.

Yip, V., \& Matthews, S. (2007). The bilingual child: Early development and language contact. Cambridge: Cambridge University Press. 